\title{
Exploring the Relevance of Regionalism to the Sustainable Building As- sessment Model in Taiwan: Through GBTool2005 Version
}

\author{
Kuei-Feng Chang ${ }^{1}$, Che-Ming Chiang ${ }^{2}$ and Po-Cheng Chou ${ }^{*}, 3$
}

\author{
${ }^{I}$ Department of Real Estate Management, National Pingtung Institute of Commerce, Taiwan, ${ }^{2}$ Department of Architec- \\ ture, National Cheng-Kung University, Tainan, Taiwan and ${ }^{3}$ Department of Interior Design, Shu-Te University, Kaohsi- \\ ung County, Taiwan
}

\begin{abstract}
From the year 1997, the work for the assessment methods of building environmental performance was prepared by ISO TC 59 SC 17 "Sustainability in building construction". It's definite that the international standard of building environmental performance is a current trend in the overall sustainable buildings. Besides, it provides a reference as a common basis between stakeholders, building owners, design teams, contractors and suppliers, et cetera. This article undertakes the AHP (Analytic Hierarchy Process) method to investigate the international demonstration sustainable building assessment tool, by compiling and completing an experts' questionnaire of professionals, the Government, professors, et cetera, in Taiwan. In addition, this study is aimed at exploring the differences between "different professionals" and "localized characteristics" of the regional effect factor, it applies the ANOVA method to clarify which is regional effect factor correlated with the assessment issues and categories. The result purposes to suit the measure to local conditions, and provide advantageously an information-bed for sustainable building assessment strategies in the future Taiwan as well.
\end{abstract}

Keywords: Sustainable building, assessment, regionalism, gbtool2005, analytic hierarchy process.

\section{INTRODUCTION}

Assessment methods are implicitly a synthesis of current environmental knowledge related to buildings, and they can focus a broad range of research through a common filter into a useful framework for design $[1,2]$. If sustainable development is to flourish in practice, it must be responsive to the particular context of environmental, social, political, economic and cultural pressures in each region. There are many frames of reference and a multiplicity of issues that cannot all be resolved by one approach [3]. Therefore, using an accepted credible assessment framework can serve as a testbed for comparing and contrasting the effectiveness of new methods and for setting performance benchmarks [4]. It also provides a way of communicating these issues to building owners and managers, architects, builders, interior designers, landscape architects, community planners, and others interested in the built environment [5]. As well in 1997, within the scope of ISO TC 59 SC 17 "Sustainability in building construction," the International Organization for Standardization tried to standardize criteria and indictors for the performance of buildings; various working groups are presently dealing with questions concerning building performance measurement [6].

In Taiwan, the Government (Architecture and Building Research Institute, Ministry of the Interior, Taiwan) established the "Green Building Evaluation and Labeling System"

*Address correspondence to this author at the Department of Interior Design, Shu-Te University, Kaohsiung County, Taiwan; Tel: +886-7-615 8000 Ext: 3510; Fax: +886-7-7416667; E-mail: paul@mail.stu.edu.tw in 1999 to promote the so-called EEWH system and was regarded as a standard evaluation method for green buildings [7]. As the new EEWH system carried out projects since the year 2005 , it is believed to be very reliable, practical and localized for green building evaluation and each indicator has its respective separately-calculating formula [8]. From the evaluated result of utilizing the EEWH system, it still hard to be exchanged region-specific topics with other assessment tools for lacking a common assessment structure, formation and issues, et cetera.

The Green Building Challenge (GBC) process, which involves several countries in the development and testing of a common framework for the assessment of sustainable performance, is of vital importance [9-12]. At the Tokyo SB05 conference, there were 25 teams involved in "the assessment case study session" to achieve the appraisal of many buildings. GBTool2005 is the mass of the sustainable building assessment tools in "the assessment case study session", and it as a reference and basis for developing a domestic assessment method $[5,13,14]$. Therefore, this paper is based on the use of GBTool2005 to carry out the expert questionnaire of the professional, the government and the academia of construction fields in Taiwan, and the application of the ANOVA method to validate a relevance of regionalism to the sustainable building assessment. It is aimed at proposing the critical effect factor of the sustainable building assessment model, and specifically to suit the measuring of Taiwan's conditions.

\section{QUESTIONNAIRE METHODOLOGY}

There are three steps in this paper, they include: the AHP method (Analytic Hierarchy Process), Normal Distribution, 
and Analysis of Variance (ANOVA). The first step is a survey phase: application of the AHP method to express quantification of the human opinions according to the GBTool2005 system [15]. The following step: employment of "Normal Distribution" to test the validity of investigated weighting values that set up by classifying groups, and then decide weights of respective groups. The final test step is through a basic knowledge of analysis of variance (ANOVA) method to measure the differences of respective groups. The methodology is shown in Fig. (1).

\subsection{AHP Method (Analytic Hierarchy Process)}

In order to express quantification of the human opinion and perception, this paper utilizes the AHP method [16-18]. The AHP modeling process involves four phases: structuring the decision problem, measurement and data collection, determination of normalized weights, and synthesis-finding solutions to the problem [19-23]. Namely, it includes decomposition of the decision-making problem into elements according to their common characteristics and the formation of a hierarchical model having different levels. Each level in the hierarchy corresponds to the common characteristic of the elements in that level.

The hierarchical structure used in formulating the AHP model can enable all members of the evaluation team to visualize the problem systematically in terms of relevant criteria and sub criteria. The team can also provide input to revise the hierarchical structure, if necessary, with additional criteria. Furthermore, using the AHP, the evaluation team can systematically compare and determine the priorities of the criteria and sub criteria.

\section{Forming a Hierarchical Model}

This research applied the nominal scale measure to form the AHP hierarchical model according to the GBTool2005 system [24] which consisted of more than three levels. The topmost level is the "total weighted result" of the GBTool2005 system. The second, third and fourth levels correspond to "Issues", "Categories" and "Criteria," but the "Criteria" level contains about 119 items. Therefore, the hierarchical structure positively take the highest three levels in the AHP model for the efficient judgment of the expert questionnaire. The AHP model is shown in Fig. (2), and each issue is respectively subdivided into several categories, that is, these categories are classified into the independent issue to set up the hierarchy.

\section{Weighting Method}

The issues and categories can be assessed using the basic AHP approach of pairwise comparisons of elements in each level with respect to every parent element located one level above. The nominal-ratio scale of pairwise comparison among the Categories represented as the score from 1 to 9 was adopted, which was filled in a positive reciprocal matrix to calculate the eigenvector and eigenvalue [25]. For each issue and category, the weighting value is obtained by the geometric mean (GMM) of experts' questionnaires, and combining the individual pairwise comparison judgment matrices to obtain the consensus pairwise comparison judgment matrices for the entire team [26, 27]. The investigated weights at the 'Issue' and 'Category' level are calculated according to equation 1 below:

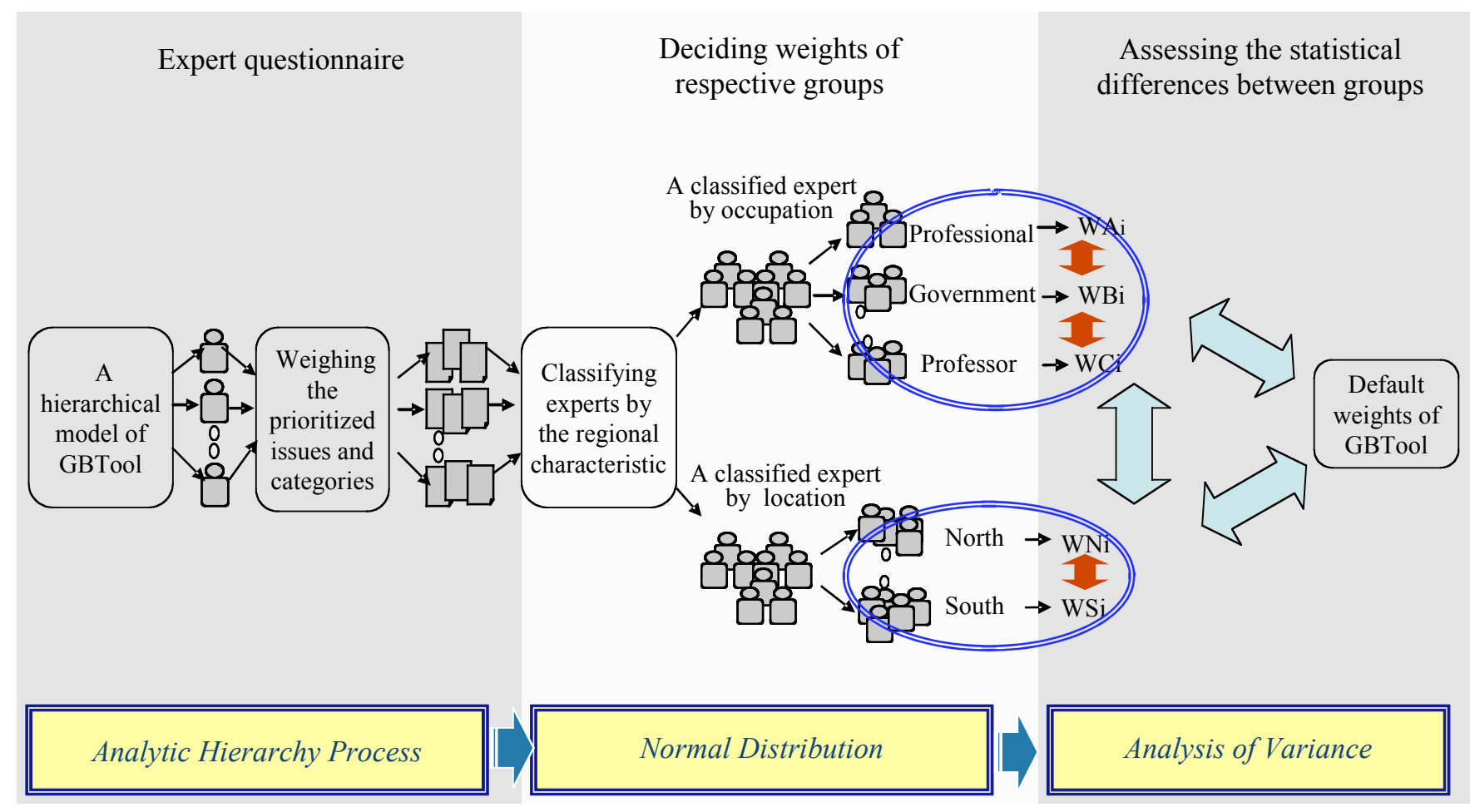

Fig. (1). The methodology of this research. 


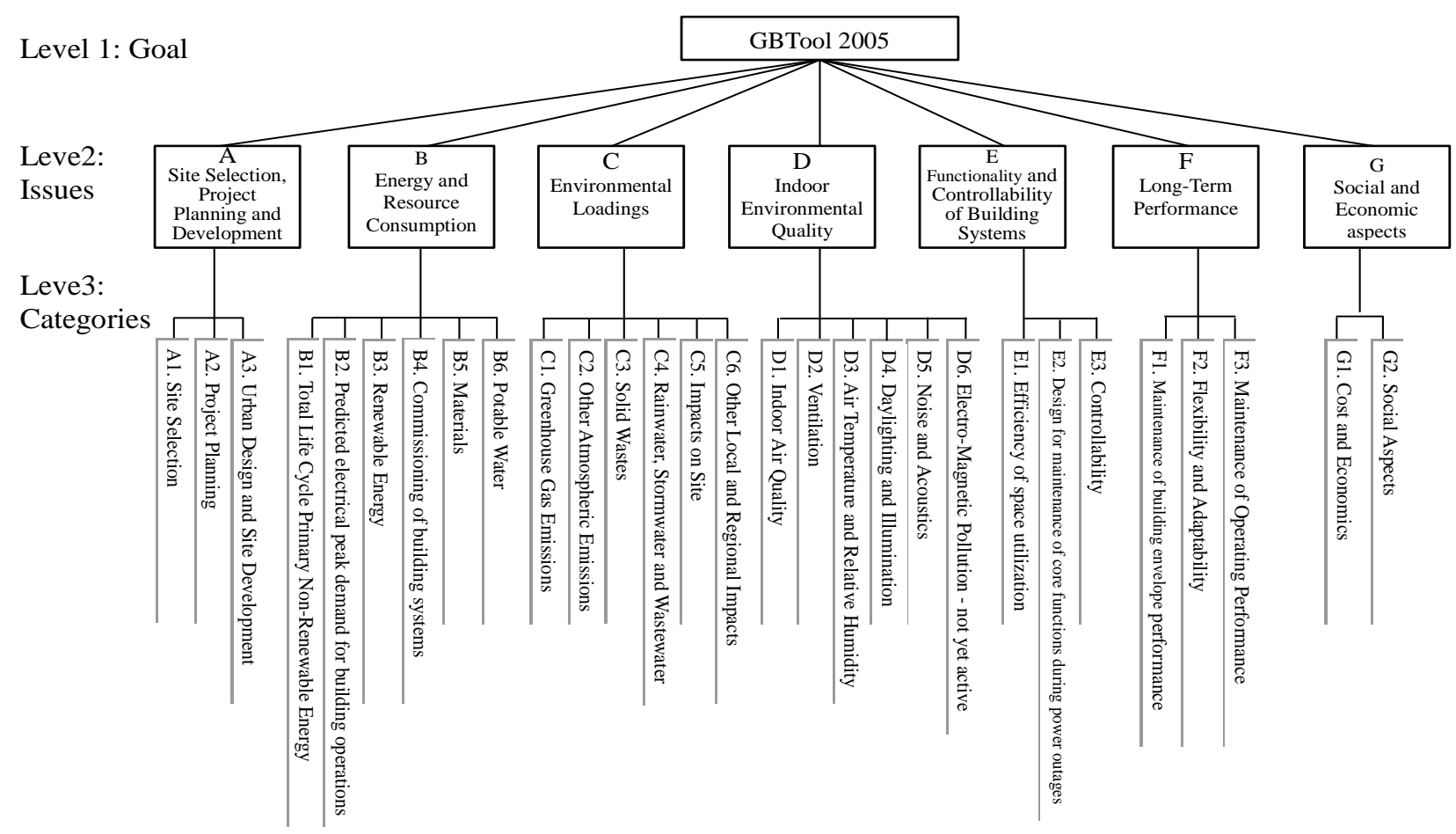

Fig. (2). The AHP model for assessment elements of GBTool2005.

$$
\mathrm{W}_{\mathrm{A}, \mathrm{i}}=\frac{\left(\prod_{j=1}^{n} a_{i j}\right)^{1 / n}}{\sum_{i=1}^{n}\left(\prod_{j=1}^{n} a_{i j}\right)^{1 / n}} \text { for } \mathrm{i}, \mathrm{j}=1,2,3 \ldots ., \mathrm{n}
$$

$\mathrm{GMM}=\left(\prod_{n=1}^{n} a_{v}\right)^{r n}$, where the index A and $\mathrm{n}$ implies "Issue" or "Category" level, and the number of "Issue" or "Category", and $\mathrm{O}_{\mathrm{i}-1}^{\mathrm{n}} \mathrm{W}_{\mathrm{A}, \mathrm{i}}=1$. (this section partially extracted from the published paper of [28])

\subsection{Study Group}

\section{Sampling Design}

Sampling characteristics represent the nature of the sample employed in measure validation research [29]. This research adopts an expert appraisal method that assumed more experience and perhaps more education in filling out questionnaires. Therefore, this sampling design belongs to a "judgment sampling", also known as purposive selection, of "nonprobability sampling". Namely, it can be suitable to a small sample from a population and can fulfill the research subject.

\section{Expert Groups}

It is important to study the opinions of experts from different fields on an identical platform. Thus, the expertise is involved with "architects and professionals", "government" and "academia and professors" expert groups, for they play a dominant role in shaping the sustainable building development and drawing up the construction policy in Taiwan.

\subsection{Classifying the Expert Questionnaire Results}

It is important to explore the influence of the regional characteristic on the sustainable building assessment model. Thus, this study groups the expert questionnaire results according to the effect factor of "occupation" and "location"

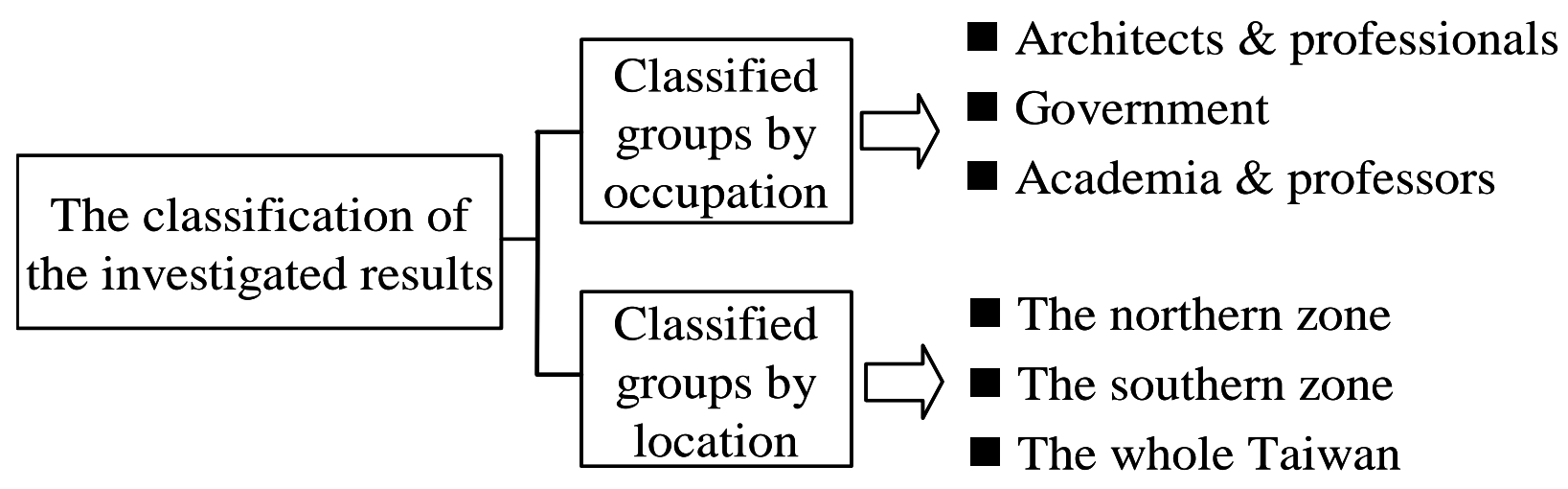

Fig. (3). The classification of the investigated results. 
respectively. The classification of the investigated results is shown in Fig. (3).

\section{Classified Groups by Occupation}

Firstly, classifying all investigated results consistent with the survey expert fields of "architects and professionals", "government," and "academia and professors" groups, in order to point out the differences between Taiwan and other countries on the sustainable building policy, construction development, and current market demand, et cetera.

\section{Classified Groups by Location}

The classification of the location factor refers to administrative division of Taiwanese building technique regulations and on the basis of the climatic characteristic, and then can be sorted into three analyzed types by "the Tropic of Cancer": the northern zone, the southern zone and the whole Taiwan. This purpose is to validate the weighting value of building assessment whether partitioned into the northern weighting value, the southern weighting value and the whole Taiwan value, or adopting directly the default weighting value of the GBTool2005 system.

\section{APPLYING STATISTICAL QUANTITATIVE ANALYSIS}

Are the questionnaire results of psychological tests replicable or repeatable? From recent articles, investigating the reliability and validity of measures has called for explicit attention in marketing research [30]. Accordantly, this paper applies with the reliability estimate and the validity estimate to obtain a proper and valued questionnaire result, and carry out a stable and precise achievement [29].

\subsection{Reliability Estimate and Validity Estimate}

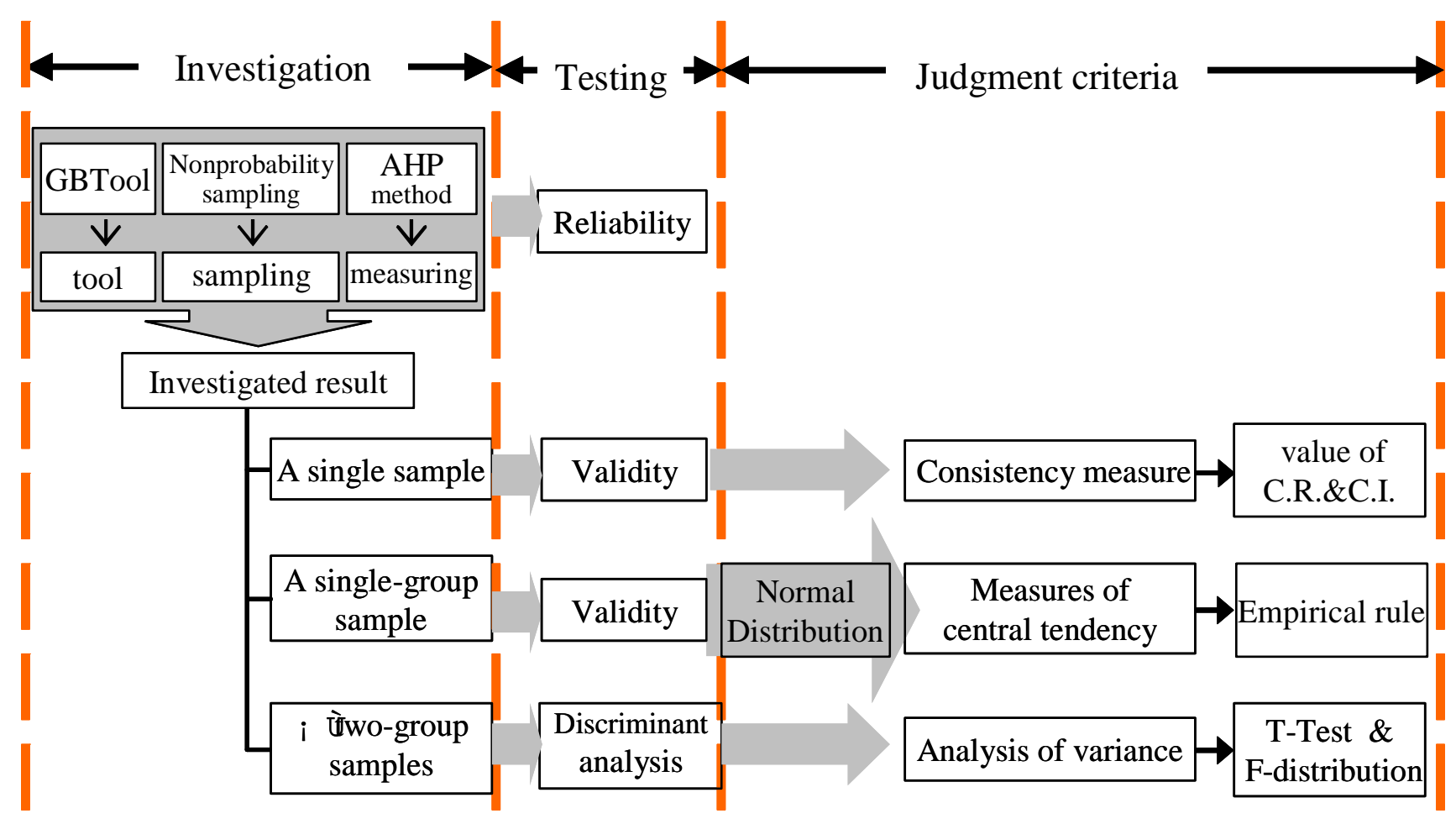

In research, the term "reliability" means "repeatability" or "consistency." Reliability estimate is the extent to which an experiment, test, or any measuring procedure yields the same result on repeated trials. A measure is considered reliable as low reliability is less detrimental to the performance pretest. But reliability is a necessary but not sufficient condition for validity.

Therefore, "validity" refers to which a study accurately reflects or assesses the specific concept that the researcher is attempting to measure. While "reliability" is concerned with the accuracy of the actual measuring instrument or procedure, "validity' is to measure the results that have the appearance of truth or reality, and provide a useful scheme for assessing the quality of research conclusions.

\subsection{Reliability Estimate of Questionnaire Development Procedure}

A careful measure development procedure that included defining the domain, searching a variety of sources for items, and specifying and then empirically investigating dimensionality, would increase a measure's reliability [30]. Thus, the reliability estimate of the questionnaire development procedure in this phase included: forming a tool, sampling, and measurement characteristics, etc...

Therefore, based on the GBTool2005 system which was developed by an ad hoc method and generally discussed in the international sustainable building conference, then, can present the relative reliability of forming a tool. In regard to the sampling and measurement characteristics, the sampling design adopts an expert appraisal method that could lead to less measurement error, and the measuring uses the AHP method (Analytic Hierarchy Process) to structure the questionnaire. Accordingly, the questionnaire development pro- 
cedure clarifies a high "reliability."

\subsection{Validity of Questionnaire Result}

The testing analysis of questionnaire result is rested with the exploring cause, which grouped the questionnaire results to the primary types of a single sample, a single-group sample, and beyond two-group samples.

\section{A Single Sample}

In order to test the validity of a single questionnaire result, it utilizes the consistency index (C.I.) of AHP method as a judgment criterion. The consistency ratio was obtained to filter out the null questionnaire when the C.I. value was greater than 0.1 .

\section{A Single-Group Sample}

Considering the research subject, the questionnaire results classified to several single-group samples. Then, this study adopts a statistical inference of "normal distribution" which involved the judgment criteria of "empirical rule", examining the validity of the group questionnaire results.

\section{Beyond Two-Group Samples}

After the foregoing sifting of the validity of the singlegroup samples, this paper proceeds to a discriminant analysis among beyond-two-group samples. Therefore, it utilizes ANOVA of T-test and F-distribution method as a judgment criterion to examine the difference among the grouped questionnaire results. The methodology of the statistical test is shown in Fig. (4).

\subsection{Normal Distribution}

The normal distribution is the most used statistical distribution. The principal reasons are: Normality arises naturally in many physical, biological, and social measurement situations.

All normal distributions are symmetric and have bellshaped density curves with a single peak. In general, the normal distribution curve is described by the following probability density function. Therefore, the normal density of investigated weights can be actually specified by means of equation 2 . The height of the density at any weighting value $x$ can be formulated by:

$f(x)=\frac{1}{\sigma \sqrt{2 \pi}} e^{-\frac{1}{2}\left(\frac{x-\mu}{\sigma}\right)}$

where the index $\mu$ and $\sigma$ implies the mean that peak of the density occurs, and the standard deviation.

Specifically, if the data appears to follow a normal distribution, then the empirical rule is preferred as it is more positive.

\section{Empirical Rule}

The empirical rule is a handy quick estimate of the data given the mean $(\mu)$ and standard deviation $(\sigma)$ of a data set that follows the normal distribution.

If a variable is normally distributed, according to the rule: within one standard deviation of the mean there will be approximately $68 \%$ of the data, i.e. in the interval $\mu \pm \sigma$; within two standard deviations of the mean there will be approximately $95 \%$ of the data, i.e. in the interval $\mu \pm 2 \sigma$; and within three standard deviations of the mean there will be approximately $99.7 \%$ of the data i.e. in the interval $\mu \pm 3 \sigma$. Then, the data distribution can fill a measure of central tendency.

Therefore, this study will apply the criteria of the empirical rule as a measure of central tendency to examine the validity of several single-group questionnaire results.

\section{TESTING THE INVESTIGATION RESULT OF AS- SESSMENT WEIGHTING VALUES}

This study sent out 50 copies to investigative experts, and received back 43 copies, which gives a response rate of $95 \%$. This section subsequently estimates the validity of "a single questionnaire result" and "a single-group questionnaire results."

\subsection{Measuring the Validity of a Single Questionnaire Result}

After filtering out the null questionnaire by the value of C.R. and C.I. that internal consistency measure of AHP method, there were 36 expertise copies that belonged to the valid questionnaire. The number of experts under consultation is 36, inclusive of twelve professionals, nine government, and professors. The total valid questionnaire experts also can be split into eighteen experts of the northern zone and eighteen experts of the southern zone according to the location factor. The expert distribution of the valid questionnaire results is shown in Fig. (5).

\subsection{Measuring the Validity of a Single Group Result on the Issue Level}

With regard to the AHP expert questionnaire of the "Issues" level of the GBTool2005 system, this part applies the criteria of Empirical Rule to examine the validity of several single-group questionnaire results via "normal distribution" and "the central tendency test."

\section{Measuring a Central Tendency of All Expert Question- naire Results}

Table 1 depicts a group test analysis on the investigated result of all experts by Empirical Rule, and all calculations of the "Issue" level conform to a measure of central tendency.

\section{Measuring a Central Tendency of Classified Groups by a Location Factor}

The major portion of issues obtained from the southern expert results conforms to a measure of central tendency. Just "B Energy and Resource Consumption" which 56\% of the data are lie in the interval $\mu \pm \sigma$ displays the entire southern expert result has a low validity on this issue at the present Taiwan. However, the whole issues of the northern expert results all filled to a measure of central tendency. (Table 2) shows a group test analysis on the investigated result of the location classified experts by Empirical Rule. 


\section{Professionals $\square$ Government $\square$ Professors}

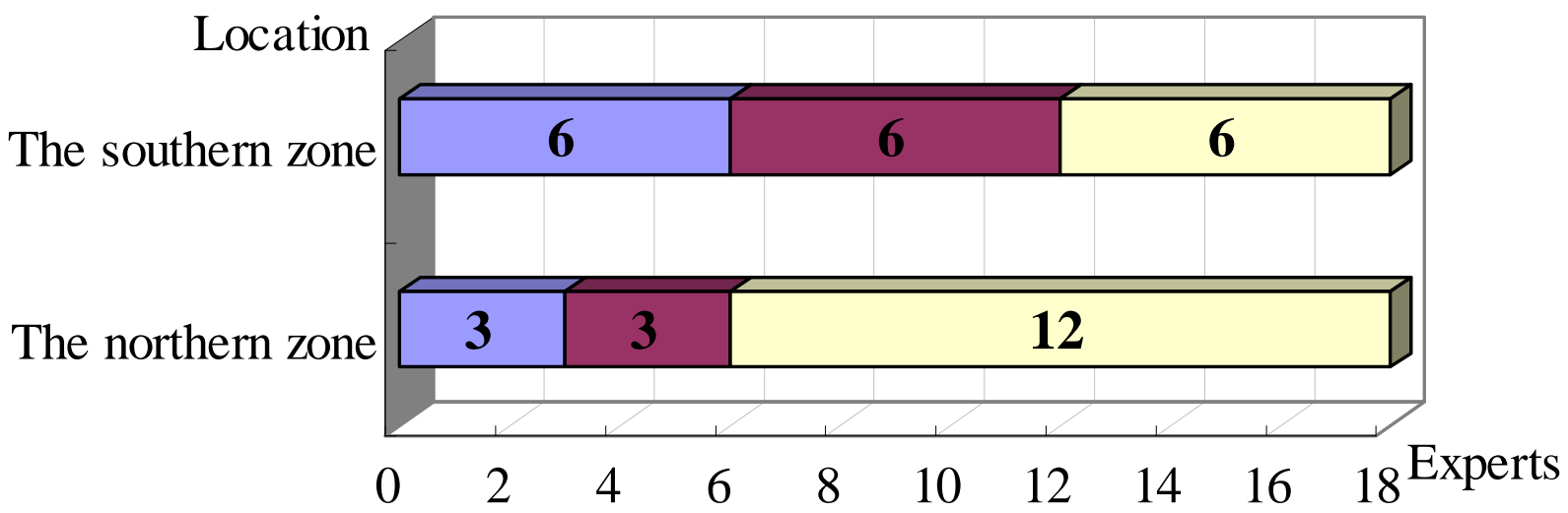

Fig. (5). The expert distribution of the valid questionnaire results.

\section{Measuring a Central Tendency of Classified Groups by an Occupation Factor}

With regard to the professional expert results, there are three issues that contain "A Site Selection, Project Planning and Development," "D Indoor Environmental Quality" and "E Functionality and Controllability of Building Systems" which can not fall in the interval $\mu \pm \sigma$, and also display a dispersive judgment in the present Taiwan. Moreover, there are two issues: "E Functionality and Controllability of Building Systems" and "G Social and Economic aspects" of the government expert results which display an invalid central tendency. However, the academics experts merely have one issue: "B Energy and Resource Consumption" that is $61 \%$ of the data in the interval $\mu \pm \sigma$, and do not have a marked central tendency. The central tendency test of three groups on the investigated result of issues is given in Table $\mathbf{3}$.

\subsection{Measuring the Validity of a Single Group Result on the Category Level}

Overall questionnaire experts, only the "E Functionality and Controllability of Building Systems" issue that possessed of above $50 \%$ "invalid" category items, and then this issue display an invalid measure of central tendency. About

Table 1. A Group Test on the Investigated Result of All Experts by Empirical Rule

\begin{tabular}{|c|c|c|}
\hline Issues of GBTool2005 & All Experts & Criteria \\
\hline \multirow{2}{*}{ A Site Selection, Project Planning and Development } & $89 \%$ & Examining values between $\mu \pm \sigma$ \\
\hline & validity & Measuring a central tendency \\
\hline \multirow{2}{*}{ B Energy and Resource Consumption } & $81 \%$ & Examining values between $\mu \pm \sigma$ \\
\hline & validity & Measuring a central tendency \\
\hline \multirow{2}{*}{ C Environmental Loadings } & $83 \%$ & Examining values between $\mu \pm \sigma$ \\
\hline & validity & Measuring a central tendency \\
\hline \multirow{2}{*}{ D Indoor Environmental Quality } & $81 \%$ & Examining values between $\mu \pm \sigma$ \\
\hline & validity & Measuring a central tendency \\
\hline \multirow{2}{*}{ E Functionality and Controllability of Building Systems } & $68 \%$ & Examining values between $\mu \pm \sigma$ \\
\hline & validity & Measuring a central tendency \\
\hline \multirow{2}{*}{ F Long-Term Performance } & $72 \%$ & Examining values between $\mu \pm \sigma$ \\
\hline & validity & Measuring a central tendency \\
\hline \multirow{2}{*}{ G Social and Economic aspects } & $69 \%$ & Examining values between $\mu \pm \sigma$ \\
\hline & validity & Measuring a central tendency \\
\hline
\end{tabular}


Table 2. A Group Test on the Investigated Result of the Location Classified Experts by Empirical Rule

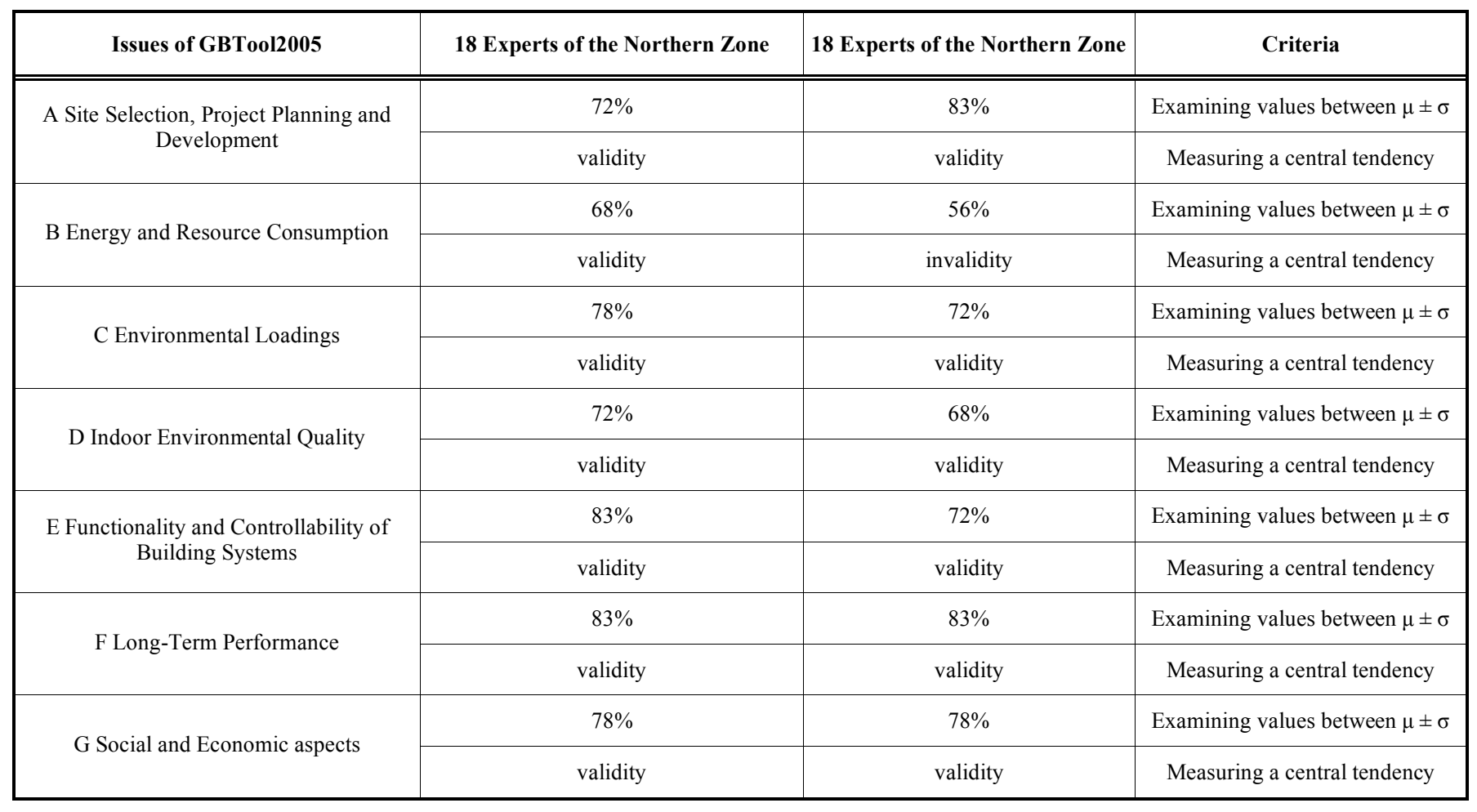

Table 3. A Group Test on the Investigated Result of the Occupation Classified Experts by Empirical Rule

\begin{tabular}{|c|c|c|c|c|}
\hline $\begin{array}{l}\text { A Site Selection, Project Planning } \\
\text { and Development }\end{array}$ & $56 \%$ & $68 \%$ & $89 \%$ & Examining values between $\mu \pm \sigma$ \\
\hline $\begin{array}{l}\text { B Energy and Resource Con- } \\
\text { sumption }\end{array}$ & $68 \%$ & $68 \%$ & $72 \%$ & Examining values between $\mu \pm \sigma$ \\
\hline C Environmental Loadings & validity & validity & invalidity & Measuring a central tendency \\
\hline \multirow{2}{*}{ D Indoor Environmental Quality } & $56 \%$ & $78 \%$ & $78 \%$ & Examining values between $\mu \pm \sigma$ \\
\hline & invalidity & validity & validity & Measuring a central tendency \\
\hline \multirow{2}{*}{ F Long-Term Performance } & $89 \%$ & $78 \%$ & $78 \%$ & Examining values between $\mu \pm \sigma$ \\
\hline & validity & validity & validity & Measuring a central tendency \\
\hline \multirow{2}{*}{ G Social and Economic aspects } & $78 \%$ & $56 \%$ & $78 \%$ & Examining values between $\mu \pm \sigma$ \\
\hline & validity & invalidity & validity & Measuring a central tendency \\
\hline
\end{tabular}

the northern and southern zone expert groups: all categories of the northern zone expert results completely conform to a measure of central tendency; but the southern zone expert results involve of three issues display an invalid measurement that each issue contains above 50\% "invalid" category items. With regard to the professional expert questionnaire, there are three issues that each issue contains above $50 \%$ "invalid" category items which represent an untrue measure of central tendency as well. However, the measurements of the professor and government only have one issue which 
Table 4. A Group Test Analysis on the Investigated Result on the Category level by Empirical Rule

\begin{tabular}{|c|c|c|c|c|c|c|c|}
\hline \multirow{2}{*}{\multicolumn{2}{|c|}{$\overbrace{\text { Assessment Categories }}^{\text {Each expert group resul }}$}} & \multirow{2}{*}{ All experts } & \multicolumn{2}{|c|}{ Location classified experts } & \multicolumn{3}{|c|}{ Occupation classified experts } \\
\hline & & & North & South & Professor & Professional & Government \\
\hline A & $\begin{array}{c}\text { Site Selection, Project Planning \& De- } \\
\text { velopment }\end{array}$ & & & & & & \\
\hline A1 & Site selection & Validity $72 \%$ & Validity $78 \%$ & Invalidity $61 \%$ & Validity $94 \%$ & Invalidity $66 \%$ & Validity $68 \%$ \\
\hline A3 & Urban design and site development & Validity $75 \%$ & Validity $83 \%$ & Validity $68 \%$ & Validity $68 \%$ & Invalidity $66 \%$ & Validity $100 \%$ \\
\hline B & Energy and Resource Consumption & & & & & & \\
\hline B1 & $\begin{array}{c}\text { Total life cycle primary non-renewable } \\
\text { energy }\end{array}$ & Validity $81 \%$ & Validity $83 \%$ & Validity $72 \%$ & Validity $78 \%$ & Validity $68 \%$ & Validity $68 \%$ \\
\hline B4 & Commissioning of building systems & Validity $78 \%$ & Validity $78 \%$ & Validity $78 \%$ & Validity $68 \%$ & Validity $89 \%$ & Validity $78 \%$ \\
\hline B5 & Materials & Validity $78 \%$ & Validity $83 \%$ & Invalidity $56 \%$ & Validity $72 \%$ & Invalidity $66 \%$ & Validity $68 \%$ \\
\hline B6 & Potable water & Validity $78 \%$ & Validity $83 \%$ & Validity $78 \%$ & Validity $72 \%$ & Validity $78 \%$ & Validity $78 \%$ \\
\hline $\mathrm{C}$ & Environmental Loadings & & & & & & \\
\hline $\mathrm{C} 1$ & Greenhouse gas emissions & Validity $72 \%$ & Validity $83 \%$ & Validity $68 \%$ & Invalidity $61 \%$ & Validity $68 \%$ & Validity $68 \%$ \\
\hline $\mathrm{C} 2$ & Other atmospheric emissions & Validity $82 \%$ & Validity $68 \%$ & Validity $68 \%$ & Invalidity $61 \%$ & Validity $89 \%$ & Validity $68 \%$ \\
\hline D1 & Indoor air quality & Validity $72 \%$ & Validity $78 \%$ & Validity $72 \%$ & Invalidity $61 \%$ & Invalidity $44 \%$ & Validity $78 \%$ \\
\hline D2 & Ventilation & Validity $75 \%$ & Validity $83 \%$ & Validity $78 \%$ & Validity $72 \%$ & Invalidity $66 \%$ & Validity $78 \%$ \\
\hline D3 & Air temperature and relative humidity & Validity $78 \%$ & Validity $68 \%$ & Validity $89 \%$ & Invalidity $61 \%$ & Validity $78 \%$ & Validity $68 \%$ \\
\hline D4 & Daylighting and illumination & $\begin{array}{l}\text { Invalidity } \\
58 \%\end{array}$ & Validity $78 \%$ & Validity $68 \%$ & Validity $78 \%$ & Invalidity $66 \%$ & Validity $68 \%$ \\
\hline D5 & Noise and acoustics & Validity $82 \%$ & Validity $78 \%$ & Validity $89 \%$ & Validity $78 \%$ & Validity $89 \%$ & Validity $78 \%$ \\
\hline D6 & $\begin{array}{l}\text { Electro-magnetic pollution - not yet } \\
\text { active }\end{array}$ & Validity $78 \%$ & Validity $83 \%$ & Validity $72 \%$ & Validity $83 \%$ & Validity $78 \%$ & Validity $78 \%$ \\
\hline $\mathrm{E}$ & $\begin{array}{c}\text { Functionality \& Controllability of } \\
\text { Building Systems }\end{array}$ & & & & & & \\
\hline E1 & Efficiency of space utilization & $\begin{array}{l}\text { Invalidity } \\
56 \%\end{array}$ & Validity $78 \%$ & Validity $68 \%$ & Validity $72 \%$ & Invalidity $66 \%$ & Validity $78 \%$ \\
\hline E2 & $\begin{array}{l}\text { Design for maintenance of core func- } \\
\text { tions outside of planned design condi- } \\
\text { tions }\end{array}$ & $\begin{array}{l}\text { Invalidity } \\
\quad 64 \%\end{array}$ & Validity $78 \%$ & Invalidity $44 \%$ & Validity $68 \%$ & Invalidity $66 \%$ & Validity $78 \%$ \\
\hline E3 & Controllability & Validity $81 \%$ & Validity $89 \%$ & Invalidity $61 \%$ & Validity $83 \%$ & Validity $78 \%$ & Validity $78 \%$ \\
\hline
\end{tabular}


Table 4. (Contd....

\begin{tabular}{|c|c|c|c|c|c|c|c|}
\hline \multirow{2}{*}{\multicolumn{2}{|c|}{$\overbrace{\text { Assessment Categories }}^{\text {Each expert group resul }}$}} & \multirow{2}{*}{ All experts } & \multicolumn{2}{|c|}{ Location classified experts } & \multicolumn{3}{|c|}{ Occupation classified experts } \\
\hline & & & \multirow[t]{2}{*}{ North } & \multirow[t]{2}{*}{ South } & \multirow[t]{2}{*}{ Professor } & \multirow[t]{2}{*}{ Professional } & \multirow[t]{2}{*}{ Government } \\
\hline $\mathrm{F}$ & Long-Term Performance & & & & & & \\
\hline F1 & Flexibility and adaptability & Validity $81 \%$ & Validity $94 \%$ & Validity $78 \%$ & Invalidity $61 \%$ & Validity $78 \%$ & Validity $78 \%$ \\
\hline G & Social and Economic aspects & & & & & & \\
\hline G1 & Cost and economics & Validity $75 \%$ & Validity $94 \%$ & \multirow{2}{*}{$\begin{array}{l}\text { Invalidity } 61 \% \\
\text { Invalidity } 56 \%\end{array}$} & Validity $72 \%$ & Validity $78 \%$ & \multirow{2}{*}{$\begin{array}{l}\text { Invalidity } 66 \% \\
\text { Invalidity } 66 \%\end{array}$} \\
\hline G2 & Social aspects & Validity $81 \%$ & Validity $78 \%$ & & Validity $72 \%$ & Validity $78 \%$ & \\
\hline
\end{tabular}

ז - Illustrated issue contains above $50 \%$ items of the category that cannot past the central tendency test.

Table 5. A Group Test Analysis on the Investigated Result on the Issue Level and the Category Level of GBTool2005 by Empirical Rule

\begin{tabular}{|c|c|c|c|c|c|c|}
\hline \multirow{2}{*}{ Assessment Issues } & \multirow{2}{*}{ All experts } & \multicolumn{2}{|c|}{ Location classified experts } & \multicolumn{3}{|c|}{ Occupation classified experts } \\
\hline & & North & South & Professor & Professional & Government \\
\hline A. Site Selection, Project Planning \& Development & $\bullet \circ$ & $\bullet \circ$ & $\bullet$ & $\bullet \circ$ & & $\bullet \circ$ \\
\hline B. Energy And Resource Consumption & $\bullet \circ$ & $\bullet \circ$ & ० & $\bullet \circ$ & $\bullet \circ$ & $\bullet \circ$ \\
\hline D. Indoor Environmental Quality & $\bullet \circ$ & $\bullet \circ$ & $\bullet \circ$ & $\bullet \circ$ & & $\bullet \circ$ \\
\hline $\begin{array}{l}\text { E. Functionality \& Controllability Of Building Sys- } \\
\text { tems }\end{array}$ & • & $\bullet$ & • & $\bullet$ & & 0 \\
\hline F. Long-Term Performance & $\bullet \circ$ & $\bullet \circ$ & $\bullet$ & $\bullet \circ$ & $\bullet$ & $\bullet \circ$ \\
\hline
\end{tabular}

- Validity issue via the central tendency test; $\circ$ Validity category via the central tendency test.

cannot fill a measure of central tendency respectively. Table 4 displays a group test analysis of the investigated result.

\subsection{Summarizing a Central Tendency Measure of the Investigation Result}

On the basis of the foregoing examining the validity of the group questionnaire results, the issues and the categories of GBTool2005 correspond to the Empirical Rule test in the majority, and still have some items of the southern zone expert and the professional expert group which have not yet reached the judgment of a central tendency measure yet. A group test analysis as shown in Table $\mathbf{5}$.

\subsection{The Investigation Result of Assessment Weighting Values}

This AHP approach derives the weights of the different expert groups indicated that the experts empirically express their opinions on the practical aspects of the recent period and the domestic situation.

The weighting value of all experts is listed in sequence: "C Environmental Loadings" (0.211), "B Energy and Resource Consumption" (0.186), "D Indoor Environmental Quality" (0.162), "A Site Selection, Project Planning and
Development" (0.118), "F Long-Term Performance" (0.111), "G Social and Economic aspects" (0.107), "E Functionality and Controllability of Building Systems" (0.105). The location classified group experts of the northern zone and the southern zone, of which the priority weighting value are: "C Environmental Loadings" $(0.211)$ and "B Energy and Resource Consumption" (0.207) respectively. The occupation classified group experts of professors and professionals, of which the priority weighting value are also: "C Environmental Loadings" (0.234) and "B Energy and Resource Consumption" (0.197) respectively.

Interestingly, the weighting value of the three issues: "C Environmental Loadings", "B Energy and Resource Consumption", and "D Indoor Environmental Quality" obviously exceeded the other four issues which the weighting value are approximate 0.1 . It means that "C Environmental Loadings", "B Energy and Resource Consumption", and "D Indoor Environmental Quality" are the critical issues of the sustainable building assessment in Taiwan.

Fig. (6) illustrates the investigated weight of the "Issues" level according to the group expert pattern. In addition, the complete investigated weight of the "Issues" and "Categories" is shown in Table 6. 


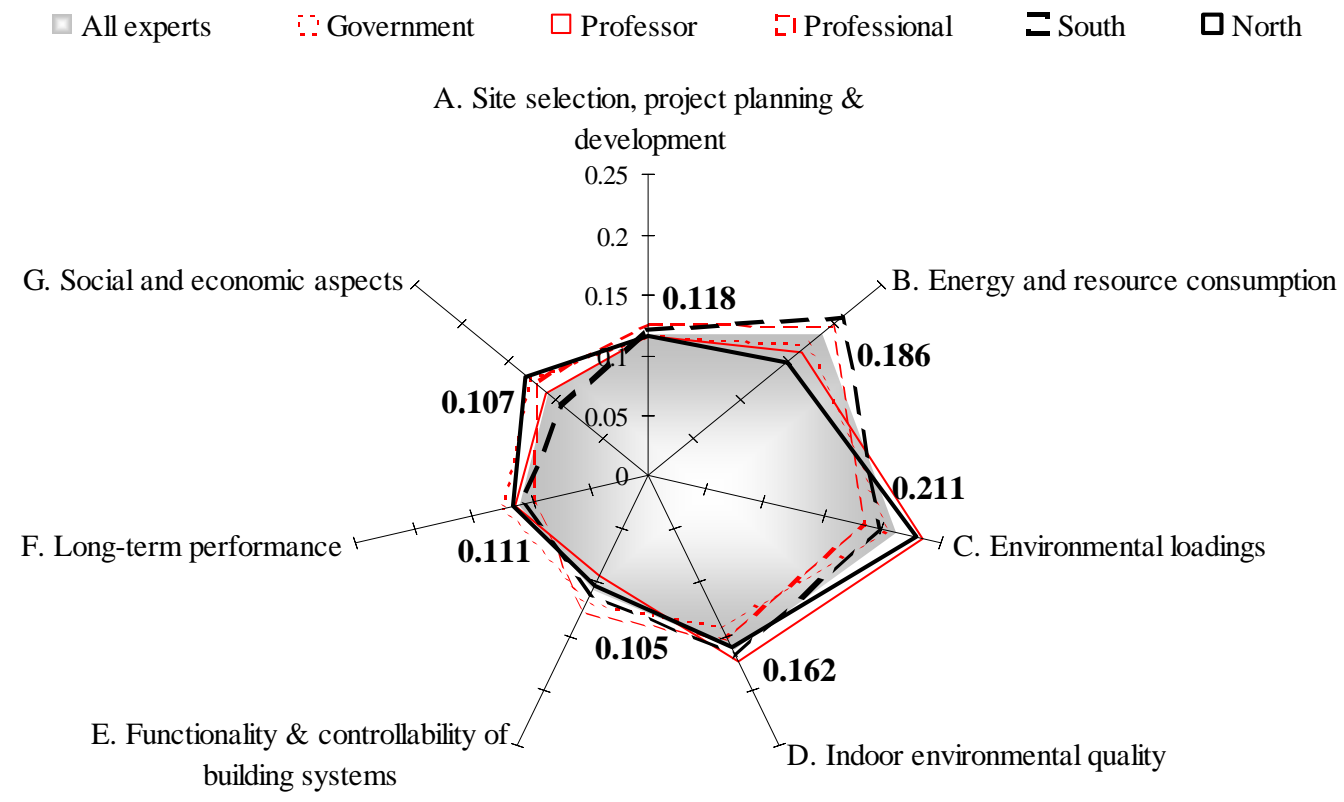

Fig. (6). The investigated weight of the different group expert patterns on the "Issues" level.

\section{ANALYZING A RELEVANCE OF A CRITICAL REGIONAL FACTOR TO THE ASSESSMENT ISSUES}

The foregoing is the majority of the single group test analysis on the Issue level and the Category level of GBTool2005 which consist with the validity of a central tendency measure. Therefore, the subsequent analysis based on "T-test" and "F-distribution" of ANOVA approach to assess the statistical differences of the investigated values between "without and within classified groups", and compare with default weights of GBTool2005. Aiming to identify whether "location effect" or "occupation effect" is the most influential parameter of classification.

\subsection{An Analysis of "Location"}

\section{Comparison Between the Northern Experts and the South- ern Experts}

The analysis of variance between the investigated values of the northern expert group and the southern expert group is: "B Energy and Resource Consumption" and "G Social and Economic aspects" both present T-value $>\mid$ Critical value $\mid$. The T-test is significant at P-value $<\alpha(0.05)$, and then the null hypothesis that there are no differences between the northern experts and the southern experts on these two issues should be rejected. Thus it should use different weighting values for the northern zone and the southern zone on the two issues when appraising buildings by GBTool2005. The T-test result is shown in Table 7.

Table 8 reports the contrast between the default weights of GBTool2005 with the investigated weight of the northern experts and the southern experts respectively. The ANOVA analysis between the investigated values of the southern expert group and the default weights included: "E Functionality and Controllability of Building Systems", "F Long-Term Performance" and "G Social and Economic aspects" present T-value $>\mid$ Critical value $\mid$. The T-test is significant at Pvalue $<\alpha(0.05)$, that is, the null hypothesis is rejected that there is significantly large different between the default weights of GBTool2005 and the southern experts on these three issues. The ANOVA analysis between the investigated values of the default weights and northern expert group is: "B Energy and Resource Consumption" and "F Long-Term Performance" present T-value $>\mid$ Critical value $\mid$. The Ttest is significant at $\mathrm{P}$-value $<\alpha(0.05)$, and the null hypothesis that there is significantly large difference between the default weights and the northern experts on the two issues.

\subsection{An Analysis of "Occupation Effect"}

\section{Comparison Among the Occupation Classified Expert Groups}

Consider these occupation classified expert groups composed of three independent samples: professional, government, and professor. The next step utilizes F-test involving the examination of the difference. In Table 9 it is seen that $\mathrm{F}$ value $>\mid$ Critical value $\mid$, and the calculation proves the null hypothesis that there is no differences among the three occupation classified expert groups is true.

The comparison of the default weights of GBTool2005 with three investigated weights of professional, government, and professor respectively is shown in Table $\mathbf{1 0}$.

The ANOVA test between the investigated values of the default weights and the professional expert group presents that T-value $>\mid$ Critical value $\mid$ at the "E Functionality and Controllability of Building Systems" issue. It means the construction professional pays more attentions on "E Functionality and Controllability of Building Systems."

The analysis of variance between the default weights and the government expert group is: "B Energy and Resource Consumption" and "F Long-Term Performance" present Tvalue $>\mid$ Critical value $\mid$. However, the investigated weight of "F Long-Term Performance" is higher than the default weight of GBTool2005. Namely, it indicates the government highlights the importance of the "F Long-Term Performance" issue on the current sustainable construction field. 
Table 6. The Investigated Weights of Each Expert Group on "Issues" and "Categories" Level

\begin{tabular}{|c|c|c|c|c|c|c|}
\hline Assessment Issues & All experts & North & South & Professor & Professional & Government \\
\hline A. Site selection, project planning \& development & 0.118 & 0.116 & 0.121 & 0.125 & 0.116 & 0.116 \\
\hline A1.Site selection & 0.315 & 0.343 & 0.305 & 0.315 & 0.315 & 0.315 \\
\hline A3. Urban design and site development & 0.355 & 0.337 & 0.361 & 0.365 & 0.363 & 0.330 \\
\hline B. Energy and Resource Consumption & 0.186 & 0.148 & 0.207 & 0.197 & 0.171 & 0.164 \\
\hline B1. Total life cycle primary non-renewable energy & 0.174 & 0.168 & 0.180 & 0.185 & 0.195 & 0.205 \\
\hline $\begin{array}{l}\text { B2. Predicted electrical peak demand for building } \\
\text { operations }\end{array}$ & 0.138 & 0.142 & 0.135 & 0.099 & 0.126 & 0.157 \\
\hline B5. Materials & 0.145 & 0.131 & 0.160 & 0.187 & 0.155 & 0.123 \\
\hline B6. Potable water & 0.195 & 0.216 & 0.175 & 0.166 & 0.176 & 0.160 \\
\hline C. Environmental Loadings & 0.211 & 0.228 & 0.197 & 0.183 & 0.204 & 0.234 \\
\hline C1. Greenhouse gas emissions & 0.183 & 0.164 & 0.210 & 0.167 & 0.223 & 0.178 \\
\hline C2. Other atmospheric emissions & 0.123 & 0.124 & 0.126 & 0.100 & 0.127 & 0.137 \\
\hline C3. Solid wastes & 0.172 & 0.175 & 0.171 & 0.178 & 0.175 & 0.168 \\
\hline D2. Ventilation & 0.214 & 0.203 & 0.24 & 0.214 & 0.215 & 0.216 \\
\hline D3. Air temperature and relative humidity & 0.164 & 0.175 & 0.158 & 0.156 & 0.187 & 0.168 \\
\hline D4. Daylighting and illumination & 0.165 & 0.153 & 0.177 & 0.180 & 0.165 & 0.154 \\
\hline D5. Noise and acoustics & 0.135 & 0.135 & 0.123 & 0.134 & 0.120 & 0.131 \\
\hline D6. Electro-magnetic pollution - not yet active & 0.100 & 0.117 & 0.077 & 0.085 & 0.100 & 0.110 \\
\hline $\begin{array}{c}\text { E. Functionality \& Controllability of Building } \\
\text { Systems }\end{array}$ & 0.105 & 0.102 & 0.109 & 0.125 & 0.117 & 0.092 \\
\hline E1. Efficiency of space utilization & 0.334 & 0.343 & 0.329 & 0.423 & 0.494 & 0.346 \\
\hline $\begin{array}{l}\text { E2. Design for maintenance of core functions outside } \\
\text { of planned design conditions }\end{array}$ & 0.336 & 0.324 & 0.352 & 0.265 & 0.249 & 0.361 \\
\hline E3. Controllability & 0.330 & 0.344 & 0.319 & 0.312 & 0.258 & 0.294 \\
\hline F. Long-Term Performance & 0.111 & 0.115 & 0.109 & 0.097 & 0.124 & 0.114 \\
\hline F1. Flexibility and adaptability & 0.449 & 0.469 & 0.435 & 0.417 & 0.513 & 0.467 \\
\hline F2. Maintenance of operating performance & 0.551 & 0.531 & 0.565 & 0.583 & 0.487 & 0.533 \\
\hline
\end{tabular}


Table 6. Contd....

\begin{tabular}{|c|c|c|c|c|c|c|}
\hline \multirow{2}{*}{ Anvestigated weights } & \multirow{2}{*}{ All experts } & \multirow{2}{*}{ Location classified experts } & \multicolumn{3}{|c|}{ Occupation classified experts } \\
\cline { 4 - 7 } & & North & South & Professor & Professional & \multirow{2}{*}{ Government } \\
\hline \hline G. Social and Economic aspects & $\mathbf{0 . 1 0 7}$ & $\mathbf{0 . 1 3 1}$ & $\mathbf{0 . 0 9 1}$ & $\mathbf{0 . 1 2 1}$ & $\mathbf{0 . 1 2 8}$ & $\mathbf{0 . 1 0 8}$ \\
\hline G1. Cost and economics & 0.509 & 0.465 & 0.556 & 0.503 & 0.502 & 0.531 \\
\hline G2. Social aspects & 0.491 & 0.535 & 0.444 & 0.497 & 0.498 & 0.469 \\
\hline
\end{tabular}

Table 7. T-Test for the Southern Expert Group and the Northern Expert Group on the Investigated Weight of "Issue"

\begin{tabular}{|c|c|c|c|c|c|c|c|}
\hline Assessment Issues & $\begin{array}{l}\text { Weights of the south- } \\
\text { ern experts }\end{array}$ & $\begin{array}{l}\text { Weights of the } \\
\text { northern experts }\end{array}$ & T-value & $\mathbf{D F}^{*}$ & $\begin{array}{c}\text { P-value } \\
\text { (two-tailor) }\end{array}$ & Critical value & Statistically significant \\
\hline $\begin{array}{l}\text { A Site Selection, Project Plan- } \\
\text { ning and Development }\end{array}$ & 0.121 & 0.116 & 0.071 & 34 & 0.944 & \pm 2.0336 & No \\
\hline $\begin{array}{l}\text { B Energy and Resource Con- } \\
\text { sumption }\end{array}$ & 0.207 & 0.148 & 2.938 & 34 & 0.006 & \pm 2.0336 & Yes \\
\hline $\begin{array}{l}\text { D Indoor Environmental Qual- } \\
\text { ity }\end{array}$ & 0.166 & 0.160 & 0.924 & 34 & 0.362 & \pm 2.0336 & No \\
\hline $\begin{array}{l}\text { E Functionality and Controlla- } \\
\text { bility of Building Systems }\end{array}$ & 0.109 & 0.102 & 0.391 & 34 & 0.698 & \pm 2.0336 & No \\
\hline F Long-Term Performance & 0.109 & 0.115 & -0.444 & 34 & 0.660 & \pm 2.0336 & No \\
\hline
\end{tabular}

* $\mathrm{DF}=$ Degree of freedom; $\mathrm{n}=($ North sample18) $+($ South sample18)-2=34.

Comparison with the default weights of GBTool 2005.

Table 8. T-test for the Default Weights of GBTool2005 with the Investigated Weight of the Northern Experts and the Southern Experts on the "Issue" Level

\begin{tabular}{|c|c|c|c|c|c|c|c|c|}
\hline & \multirow{2}{*}{$\begin{array}{c}\text { GBTool2005 } \\
\text { Assessment issues }\end{array}$} & $\begin{array}{c}\text { Critical } \\
\text { value } \\
(\boldsymbol{\alpha}=\mathbf{0 . 0 5})\end{array}$ & \multicolumn{2}{|c|}{ Experts of the southern zone* } & \multicolumn{3}{|c|}{ Experts of the northern zone* } \\
\cline { 5 - 8 } & & weights & T-value & Statistically significant & weights & T-value & Statistically significant \\
\hline \hline $\begin{array}{c}\text { A Site Selection, Project Plan- } \\
\text { ning and Development }\end{array}$ & 0.125 & \pm 2.110 & 0.121 & -0.0311 & No & 0.116 & -0.0669 & No \\
\hline $\begin{array}{c}\text { B Energy and Resource Con- } \\
\text { sumption }\end{array}$ & 0.208 & \pm 2.110 & 0.207 & -0.2184 & No & 0.148 & -6.0879 & Yes \\
\hline C Environmental Loadings & 0.208 & \pm 2.110 & 0.197 & -1.0985 & No & 0.228 & 0.8375 & No \\
\hline $\begin{array}{c}\text { D Indoor Environmental Qual- } \\
\text { ity }\end{array}$ & 0.167 & \pm 2.110 & 0.166 & -0.3230 & No & 0.160 & -0.8361 & No \\
\hline $\begin{array}{c}\text { E Functionality and Controlla- } \\
\text { bility of Building Systems }\end{array}$ & 0.083 & \pm 2.110 & 0.109 & 2.3401 & Yes & 0.102 & 1.5972 & No \\
\hline F Long-Term Performance & 0.083 & \pm 2.110 & 0.109 & 2.1900 & Yes & 0.115 & 2.3069 & 1.1819 \\
\hline G Social and Economic aspects & 0.125 & \pm 2.110 & 0.091 & -2.6691 & Yes & 0.131 & No \\
\hline
\end{tabular}

* DF=Degree of freedom; $\mathrm{n}=($ North sample18) or (South sample18) $-1=17$. 
Table 9. F-Distribution for Professional, Government and Professor Expert Groups on the Investigated Weight of "Issue"

\begin{tabular}{|c|c|c|c|c|c|c|c|}
\hline Assessment Issues & Professional & Government & Professor & F-value & $\mathrm{DF}^{* 1}$ & Critical Value $^{* 2}$ & Statistically Significant \\
\hline $\begin{array}{l}\text { A Site Selection, Project Plan- } \\
\text { ning and Development }\end{array}$ & 0.125 & 0.116 & 0.116 & 0.110 & 33 & $3.293(0.051)$ & No \\
\hline $\begin{array}{l}\text { B Energy and Resource Con- } \\
\text { sumption }\end{array}$ & 0.197 & 0.171 & 0.164 & 1.689 & 33 & $3.293(0.051)$ & No \\
\hline C Environmental Loadings & 0.183 & 0.204 & 0.234 & 1.782 & 33 & $3.293(0.051)$ & No \\
\hline $\begin{array}{l}\text { E Functionality and Controllabil- } \\
\text { ity of Building Systems }\end{array}$ & 0.125 & 0.117 & 0.092 & 1.820 & 33 & $3.293(0.051)$ & No \\
\hline F Long-Term Performance & 0.097 & 0.124 & 0.114 & 0.927 & 33 & $3.293(0.051)$ & No \\
\hline G Social and Economic aspects & 0.121 & 0.128 & 0.108 & 0.226 & 33 & $3.293(0.051)$ & No \\
\hline
\end{tabular}

*1 DF=Degree of freedom; $\mathrm{n}=($ Total sample 36$)-3=33$.

$* 2$ Critical value: F-value $<3.293$ or F-value $>0.051$, there is significant difference among theses three independent samples.

Comparison with the default weights of GBTool2005.

Table 10. T-test for the Default Weights of GBTool2005 with the Investigated Weight of Professional, Government and Professor Expert Groups on the "Issue" Level

\begin{tabular}{|c|c|c|c|c|c|c|c|c|c|}
\hline Assessment Issues & $\begin{array}{c}\text { GBTool2005 } \\
\text { (default) }\end{array}$ & \multicolumn{3}{|c|}{ Professional $^{* 1}$} & \multicolumn{2}{|c|}{ Government $^{* 1}$} & \multicolumn{3}{|c|}{ Professor $^{* 2}$} \\
\hline $\begin{array}{l}\text { A Site Selection, Project Plan- } \\
\text { ning and Development }\end{array}$ & 0.125 & \pm 2.306 & -0.021 & No & 0.186 & No & \pm 2.101 & 0.183 & No \\
\hline C Environmental Loadings & 0.208 & \pm 2.306 & -1.596 & No & -0.669 & No & \pm 2.101 & 1.146 & No \\
\hline D Indoor Environmental Quality & 0.167 & \pm 2.306 & -1.147 & No & -2.180 & No & \pm 2.101 & 0.117 & No \\
\hline $\begin{array}{l}\text { E Functionality and Controllabil- } \\
\text { ity of Building Systems }\end{array}$ & 0.083 & \pm 2.306 & 2.579 & Yes & 1.755 & No & \pm 2.101 & 0.791 & No \\
\hline
\end{tabular}

*1 DF=Degree of freedom; $n=($ Professional sample9) or $($ Government9)-1=8; Critical value $= \pm 2.306$.

*2 DF=Degree of freedom; $\mathrm{n}=$ (Professor sample18)-1=17; Critical value $= \pm 2.101$.

\section{DETERMINE A CRITICAL REGIONAL FACTOR}

6.1. "Location Effect" vs. "Occupation Effect" on the Issue Level

Refer to the aforementioned ANOVA measurements. From (Table 11) it is clear that there is a significant variance between the southern expert group and the northern expert group on the two issues: "B Energy and Resource Consumption" and "G Social and Economic aspects". In addition, there is no difference among the occupation classified expert groups. Accordingly, the "location effect" is a critical regional factor to determine the sustainable assessment issues of GBTool2005 for appraising buildings in Taiwan.

\subsection{The Investigated Weight vs. the Default Weight on the Issue Level}

In Table $\mathbf{1 2}$ it is seen the calculation proves that there is a significant difference between the investigated average weights and the default weights on "B Energy and Resource Consumption", "E Functionality and Controllability of Building Systems" and "F Long-Term Performance". Specifically, the investigated weights of "E Functionality and Controllability of Building Systems" and "F Long-Term Performance" are both larger than the default weights. It indicates that Taiwan's experts suggest paying more attention to the two issues on the sustainable building assessment aspect.

\subsection{A Discussion on the Assessment Categories}

This phase still applies the ANOVA method to measure the variance within "the location classified expert groups" and "the occupation classified expert groups" respectively on the category level. However, there are no differences not only between the northern zone experts and the southern zone experts, and but also among professional, government, and professor. Thus, "location effect" and "occupation ef- 
Table 11. The ANOVA Analysis for Comparison Between "Location Effect" and "Occupation Effect" on the "Issue" Level

\begin{tabular}{|c|c|c|c|c|c|}
\hline \multirow{2}{*}{ Assessment Issues } & \multicolumn{2}{|c|}{ Location Classified Experts } & \multicolumn{3}{|c|}{ Occupation Classified Experts } \\
\hline & Southern Experts & Northern Experts & Professional & Government & Professor \\
\hline $\begin{array}{c}\text { A Site Selection, Project Planning and De- } \\
\text { velopment }\end{array}$ & - & - & - & - & - \\
\hline B Energy and Resource Consumption & $\boldsymbol{\Delta}$ & $\boldsymbol{\nabla}$ & - & - & - \\
\hline C Environmental Loadings & - & - & - & - & - \\
\hline D Indoor Environmental Quality & - & - & - & - & - \\
\hline $\begin{array}{l}\text { E Functionality and Controllability of Build- } \\
\text { ing Systems }\end{array}$ & - & - & - & - & - \\
\hline F Long-Term Performance & - & - & - & - & - \\
\hline G Social and Economic aspects & $\nabla$ & $\Delta$ & - & - & - \\
\hline
\end{tabular}

Table 12. T-test for the Default Weights of GBTool2005 with the Investigated Weight of All Experts on the "Issue" Level

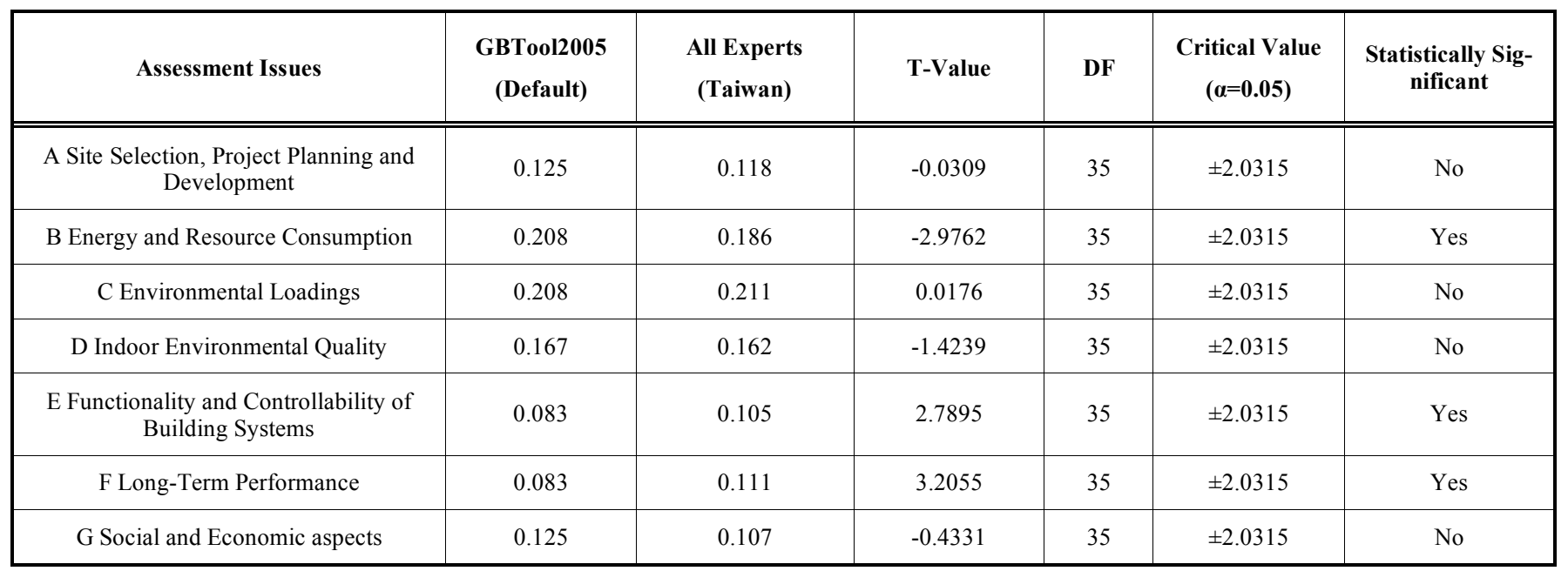

fect" can not be regard as a classified treatment on the category level in Taiwan.

Table 13 reports a significant difference between all the investigated weights and the default weights such as these categories mostly within "B Energy and Resource Consumption", "C Environmental Loadings" and "D Indoor Environmental Quality" issues.

\section{CONCLUSION}

Based on the assessment framework of GBTool2005, this study can provide a regional customization of GBTool2005 in Taiwan, and announce a set of feasible weighting values applied to evaluate the performance of buildings. The results can be summarized in the following points:

(1) The AHP result of experts' opinions outlines the priority issues in Taiwan. They are: 'C. Environmental Loadings,' of which the weighting value is $21.1 \%$, 'B. Energy and Resource Consumption,' of which the weighting value is $18.6 \%$, and ' $\mathrm{D}$ Indoor Environmental Quality,' of which the weighting value is $16.2 \%$.

(2) The ANOVA statistical inference clarifies that "location characteristics" is the critical factor to influence the assessment weighting value. Therefore, the default weights of GBTool2005 can be adapted regionally to three sets of the weighting value on the firstlevel "Issues": "the northern zone", "the southern zone" and "the whole Taiwan"; meanwhile, the second-level "Categories" can be grouped into one weighting value set of the whole Taiwan area shown as the marked area in Table $\mathbf{1 3}$.

(3) Overall, (Fig. 7) illustrates the simple formulation of the "Issues" level: "A. Site Selection, Project Planning and Development," "C. Environmental Loading" and "D. Indoor Environmental Quality" continue using the weighting value of GBTool2005; "B Energy 
Table 13. T-Test for the Default Weights of GBTool2005 with the Investigated Weight of All Experts on the "Category" Level

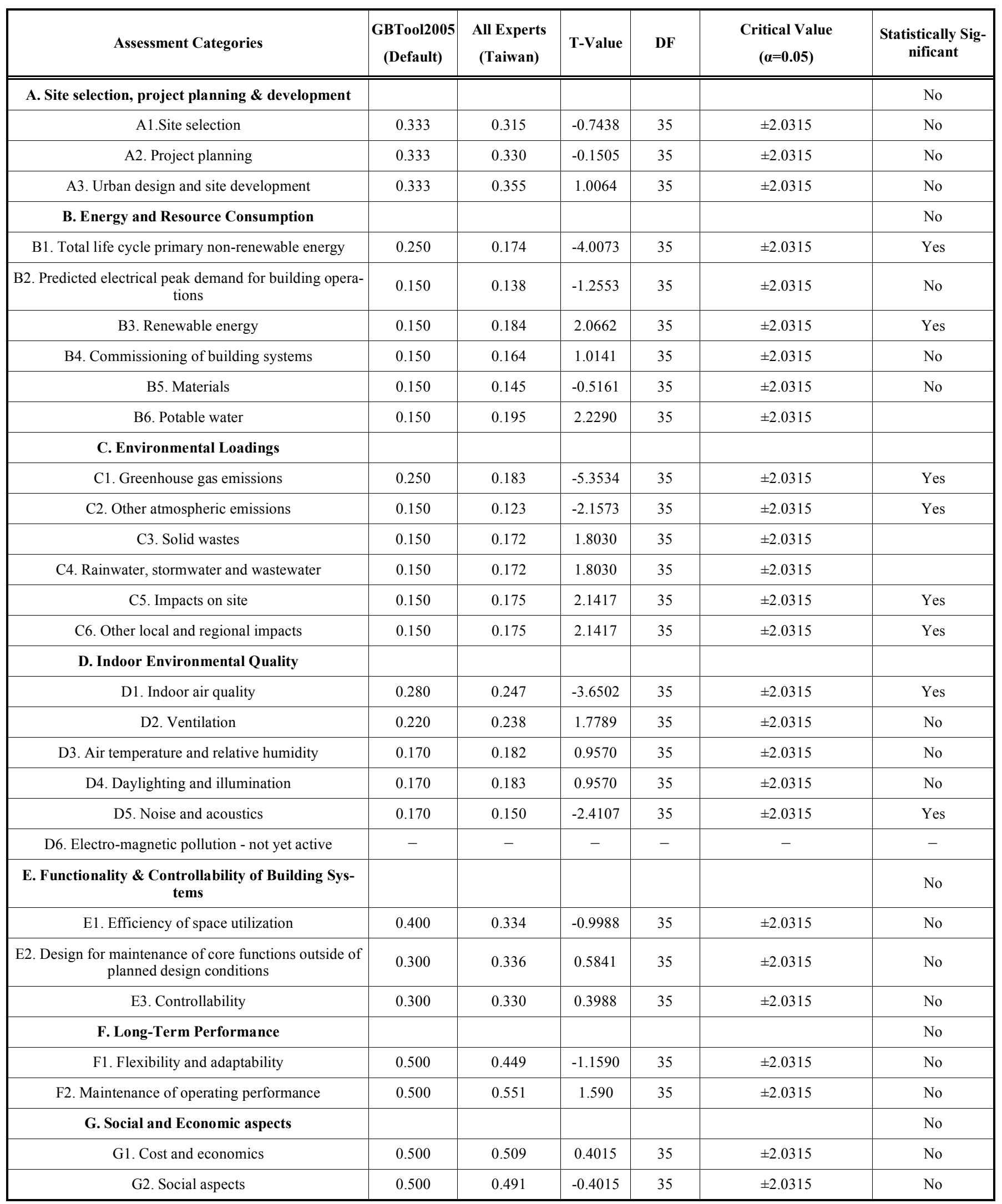

and Resource Consumption", "E Functionality and Controllability of Building Systems", "F Long-Term
Performance" and "G Social and Economic aspects" should be modified on the basis of the building's lo- 


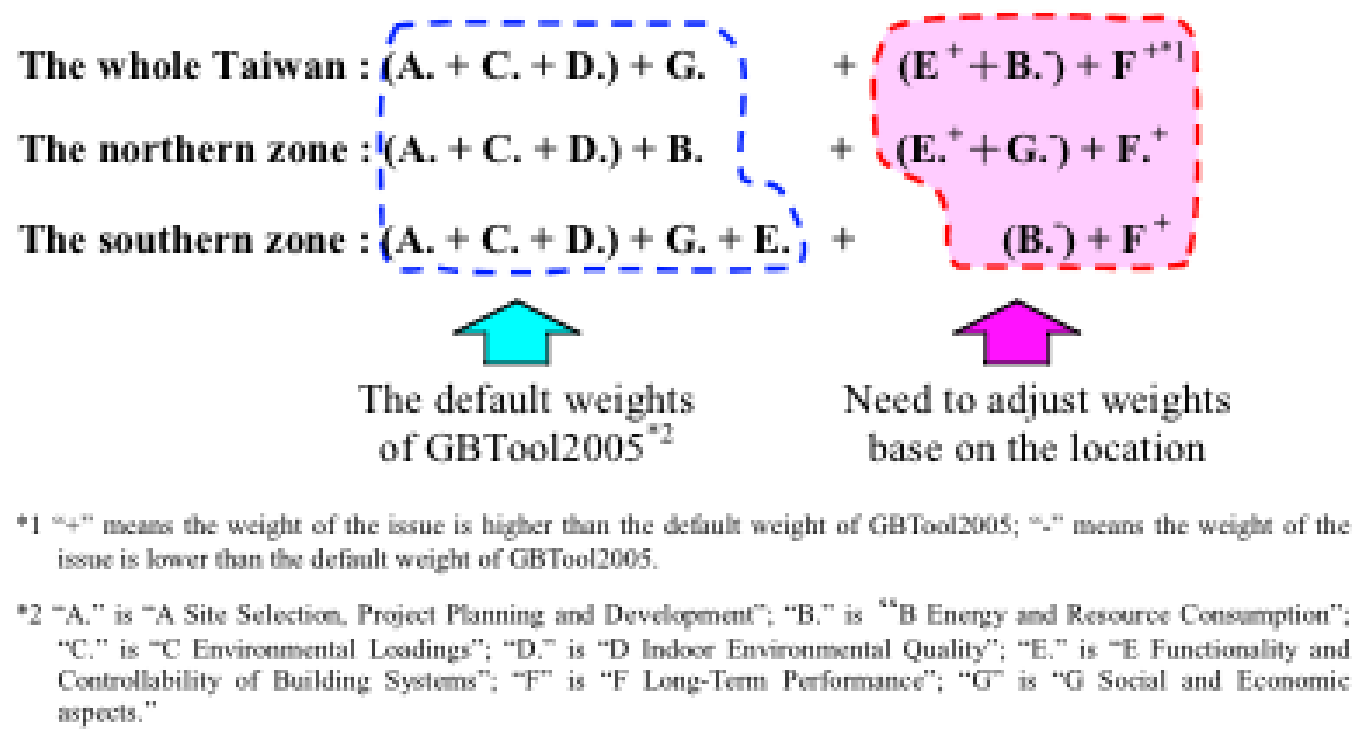

Fig. (7). The simple formulation of the weighting value on the "Issues" level of GBTool2005.

cation. In addition, "F Long-Term Performance" is a critical issue as the weight is significant "higher" than the default weight whatever the building is located. The "Category" level of "B. Energy and Resource Consumption," "C. Environmental Loading" and "D. Indoor Environmental Quality" select the average result of all experts' questionnaires; the rest categories use the default value of GBTool2005.

\section{ACKNOWLEDGEMENTS}

Support from the National Science Council of ROC through grant No. NSC 93-2218-E-366-001-, NSC 94-2218E-006-045-, NSC 95-2218-E-006-022-, NSC 96-2218-E006-004-, and NSC 95-2221-E-366-017-MY2 in this study is gratefully acknowledged. And, the support of Nils Larsson (iiSBE) in clarifying certain issues relating to $\mathrm{GBC}$ and GBTool2005 is acknowledged.

\section{REFERENCES}

[1] N. K. Larsson and R. J. Cole, "GBC '98: context, History and Structure", in Conference Proceedings of Green Building Challenge '98 Conference, Vancouver, Canada, 1998.

[2] N. K. Larsson, "Development of a Building Performance Rating and Labelling System in Canada", Building Research \& Information, vol. 27(4), pp. 332-341, 1999.

[3] R. Lorch, "Sustainable Development and Regionalism", Building Research \& Information, vol. 33(5), pp. 393-396, 2005.

[4] R. J. Cole, "Emerging trends in building environmental assessment methods", Building Research \& Information, vol. 26(1), pp.3-16, 1998.

[5] J.A. Todd, D. Crawley, S. Geissler and G. Lindsey. "Comparative Assessment of Environmental Performance Tools and the Role of the Green Building Challenge", Building Research \& Information, vol. 29(5), pp. 324-335, 2001.

[6] T. L. Tzkendorf and D. Lorenz, "Sustainable property investment: valuing sustainable buildings through property performance assessment, Building Research \& Information, vol. 33(3), pp. 212234, 2005.

[7] Architecture and Building Research Institute, Ministry of the Interior, Taiwan, Evaluation Manual for Green Building in Taiwan (English ed.), 2003.

[8] H. T. Lin, "New Rating System for Green Building Assessment in Taiwan Based on a Database of 185 Evaluated Governmental
Buildings", in Conference Proceedings of The 2005 World Sustainable Building Conference, Tokyo, 2005.

[9] R. J. Cole, "Building Environmental Assessment Methods: Clarifying Intentions", Building Research \& Information, vol. 27(4), pp. 230-246, 1999.

[10] N. K. Larsson, Ed., Review of GB-Tool and Analysis of GBC 2002 Case-Study Projects, 2002.

[11] R. J. Cole, "Changing context for environmental knowledge", Building Research \& Information, vol. 32(2), pp. 91-109, 2004.

[12] N.K. Larsson, "Regionalism and sustainable development: genesis of SB04”, Building Research \& Information, vol. 33(5), pp. 397404, 2005.

[13] D. Crawley and I. Aho, "Building Environmental Assessment Methods: Applications and Development Trends", Building Research \& Information, vol. 27(4), pp. 300-308, 1999.

[14] M. Deakin, P. Huovila, S. Rao, M. Sunikka and R. Vreeker, "The Assessment of Sustainable Urban Development", Building Research \& Information, vol. 30(2), pp. 95-108, 2002.

[15] G. E. Pavlikakis and V. A. Tsihrintzis, "A quantitative method for accounting human opinion, preferences and perceptions in ecosystem management", Journal of Environmental Management", vol. 68, pp. 193-205, 2003.

[16] T. L. Satty and E. Erdener, "A new approach to performance measurement the analytic hierarchy process", Design Methods and Theories, vol. 13(2), pp. 62-68, 1979.

[17] T. L. Saaty, The Analytic Hierarchy Process: Planning, Priority Setting and Resource Allocation, New York: McGraw-Hill, 1980.

[18] J. P. Shim, "Bibliographical Research on the Analytic Hierarchy Process (AHP)", Socio-Economic Planning Sciences, vol. 23, pp. 161-167, 1989.

[19] M. C. Y. Tama and V. M. R. Tummala, "An application of the AHP in vendor selection of a telecommunications system", Omega, vol. 29, pp. 171-182, 2001.

[20] R. A. Ramanathan, "A note on the use of the analytic hierarchy process for environmental impact assessment", Journal of Environmental Management, vol. 63, pp. 27-35, 2001.

[21] I. Basak and T. L. Saaty, "Group decision making using the analytic hierarchy process", Mathematical and Computer Modeling, vol. 17, pp. 101-109, 1993

[22] C. M. Chiang and C. M. Lai, "A study on the comprehensive indicator of indoor environment assessment for occupants' health in Taiwan”, Building and Environment, vol. 37, pp. 387-392, 2002.

[23] C. M. Chiang, P. C. Chou, C. M. Lai and Y. Y. Li, "A Methodology to Assess the Indoor Environment in Care Centers for Senior Citizens", Building and Environment, vol. 36, pp. 561-568, 2001.

[24] International Initiative for a Sustainable Built Environment (iiSBE), GBC Green Building Tool, 2005. www.iisbe.org/iisbe/-start/iisbe.ht. 
[25] K. M. A. S. Al-Harbi, "Application of the AHP in project management", International Journal of Project Management, vol. 19, pp. 19-27, 2001.

[26] T. L. Saaty, Fundamentals of decision making and priority theory with the analytic hierarchy process, Pittsburg: RWS Publications, 2000.

[27] J. Aczel and T. L. Saaty, "Procedures for synthesizing ratio judgments", Journal of Mathematical Psychology, vol. 27, pp. 93-102, 1983.
[28] K. F. Chang, C. M. Chiang and P. C. Chou "Adapting aspects of GBTool 2005-searching for suitability in Taiwan", Building and Environment, vol. 42(1), pp. 310-316, 2007.

[29] J. P. Peter and J. G. A Churchill, "Relationships among research design choices and psychometric properties of rating scales: a meta-analysis", Journal of Marketing Research, vol. 23(1), p. 1-10, 1986.

[30] G. A. Churchill Jr. and J. P. Peter, "Research Design Effects on the Reliability of Rating Scales: A Meta-Analysis", Journal of Marketing Research, vol. 21(4), pp. 360-375, 1984.

(C) Po-Cheng Chou et al.; Licensee Bentham Open.

This is an open access article licensed under the terms of the Creative Commons Attribution Non-Commercial License (http://creativecommons.org/licenses/by-nc/3.0/) which permits unrestricted, non-commercial use, distribution and reproduction in any medium, provided the work is properly cited. 